\title{
Risk perceptions starting to shift? U.S. citizens are forming opinions about nanotechnology
}

\author{
Susanna Priest • Ted Greenhalgh • Victoria Kramer
}

Received: 22 May 2009/Accepted: 19 October 2009/Published online: 5 November 2009

(C) Springer Science+Business Media B.V. 2009

\begin{abstract}
This article presents early results from an opinion formation study based on a 76-member panel of U.S. citizens, with comparison data from a group of 177 nanotechnology experts. While initially similar to the expert group in terms of their perceptions of the risks, benefits, and need for regulation characterizing several forms of nanotechnology, the first follow-up survey indicates that the panel is beginning to diverge from the experts, particularly with respect to perceptions of the levels of various "societal" risks that nanotechnology might present. The data suggest that responding to public concerns may involve more than attention to physical risks in areas such as health and environment; concerns about other forms of risk actually appear more salient.
\end{abstract}

Keywords Risk perception - Benefit perception Need for regulation - Opinion formation . Panel study · Nanotechnology · Nanoscience · Nanoengineering $\cdot$ Societal implications

S. Priest $(\square) \cdot$ T. Greenhalgh

University of Nevada, Las Vegas, NV, USA

e-mail: susanna.priest@unlv.edu

T. Greenhalgh

e-mail: ted.greenhalgh@unlv.edu

V. Kramer

University of South Carolina, Columbia, SC, USA

e-mail: chitari@yahoo.com
This article reports on the first two waves of survey data collected from a small panel study of U.S. citizens in South Carolina, with baseline comparison data from a national group of published nanotechnology experts. This comparison is specifically designed to capture the dynamics of early phase opinion formation in the initial period after enrolling in the study; the results reveal modest, but noticeable elevations in perceived risk. Subsequent analysis will consider longer-term trends. While initially quite close to the experts in terms of their perceptions of most risks and benefits, the 76-member citizens' panel began, and remains, more concerned about a variety of what we term "societal risks" such as economic, distributional, and privacy issues than about health or environmental risks. Citizens' panel members are also more in favor of regulation than nanotechnology experts, despite foreseeing roughly equivalent benefits. In our first follow-up survey of the panel, as reported here, we note a small, but quite visible increase in panel members' perceptions of health risks and rising concern about a range of societal risks, particularly privacy, which panelists appear to perceive nanotechnology as likely to erode.

Scientists continue to express enthusiasm about the promise of nanotechnology, while also revealing increasing concern over how to evaluate its potential toxicity (Service 2008; Shatkin 2008). Recently, journals in this area appear to have been devoting much more space to assessing nanotoxicity; the third of three special issues on this topic in the Journal of 
Nanoparticle Research appeared as the January 2009 issue, reflecting the increased recognition and attention given to potential health and environmental risks. It is now widely acknowledged that nanotechnology exposure, especially among workers but also for the eventual consumers of nano-related products, carries physical risks, and that these are poorly understood, with the regulatory community scrambling to get on top of this situation at the federal, state, and sometimes local level. However, within the scientific community, "upstream" scientists developing nanotechnology may still have different views on issues of potential risk than "downstream" scientists trained to evaluate health and environmental impacts (Powell 2007).

Previous research has already indicated that nonexpert citizens appear to be at least as concerned about the societal risks of nanotechnology as they are about threats to health and the environment (Priest and Fussell 2006; Cobb and Macoubrie 2004). Our data suggests that this gap between perceived health and environmental risks and perceived societal risks is increasing. We argue, therefore, that if the scientific and engineering communities want to be responsive to public concerns, addressing health and environmental impacts is certainly necessary, but not sufficient. In otherwise democratic societies, policy that ignores the full range of public concerns or avoids responding to public input risks the potential public rejection of an entire class of technology, as evidenced by the current state of nuclear power in the U.S. and genetically modified organisms worldwide. Not only does early public involvement connect the citizenry to policy-making, but it also illuminates problems that might have been overlooked by policy makers and allows citizen "expertise" to inform the decision process.

Public awareness and concern about nanotechnology and its potential risks remains low. According to a national study released by Hart Research in 2008, $75 \%$ of those polled said they had heard little or nothing at all about nanotechnology, and $65 \%$ of those who had heard nothing have no opinion about it. Of those who have heard about nanotechnology, only $8 \%$ believe the risks outweigh the benefits. Results from the South Carolina citizens' panel (see "Methods" below) are not intended to be generalizable to the U.S. population in terms of specific opinions; indeed, both African-Americans and conservative Christians-groups the same Hart Research study identified as likely less optimistic about nanotech's benefits than the American average-were deliberately included among our panelists, along with other ordinary citizens, Columbia community leaders, and members of an environmental group. Nevertheless, our panel members are very much like the general American population in being largely uninformed and mostly positive about nanotechnology.

Based on initial face-to-face interviews conducted prior to administering the initial set of quantitative survey instruments, it seems to us that reactions to nanotechnology follow a "template" generated from exposure to previous technologies, in the absence of specific information or clear pre-existing mental images of what nanotechnology might be. Americans are largely positive about technology, and they continue to trust scientists (NSF 2008, p. 737). Yet, they also expect technology to carry risks as well as benefits (Priest and Kramer 2008). Their reactions likely derive from these generalized expectations as much as specific reactions to nanotechnology (which was defined for them prior to actual survey administration). They may also reflect generalized concerns about privacy, the economy, regulatory adequacy, and so on, as well as patterns of trust or distrust.

How the public comes to view a new technology is not created along the lines that traditional risk or costbenefit analysis might predict. The lay public forms its opinions from a variety of innate and external information, biases, and associations. The Social Amplification of Risk Framework (Kasperson et al. 1988) details some of the ways various social institutions can amplify, maintain, or attenuate the public's perception of a risk. Unlike what is assumed by the models used by the trained risk analyst calculating the probability of an adverse event, risk information rarely travels directly from the sender (expert) to the receiver (public). Instead, the information travels through many intermediaries, each of which filters, processes, and then passes along the message. As these intermediaries, which include expert sources, journalists, interpersonal contacts, and a host of other actors, are all influenced in complex ways by a variety of social or cultural factors, the amplification of risk framework attempts to integrate theories from a number of social and behavioral science fields. 
Communication theories can offer some insight into how the panel group evaluates nanotechnology. While our initial introduction of the topic to these individuals may increase their awareness (acting as a priming effect), agenda-setting theory (McCombs and Shaw 1993) predicts that extended mass media coverage of an issue (in this case, nanotechnology or some perceived personal impact of this technology) will increase salience and capture people's continued attention. How this affects perception can also be influenced by how the media stories are framed. Framing attempts to set the limits for how a topic is discussed by selecting and omitting certain elements, information, phrases, and words (Entman 1993). While sometimes done strategically in a conscious attempt to influence public reception, framing is also an inevitable consequence of the way news work is done, and stories are created (Tuchman 1978). Knowledge gap theory (Tichenor et al. 1980) predicts that some demographic groups will have access to different levels of information about an emerging controversy than others, and further that local media may be less likely to cover conflict than regional or national media. Taken together, these three ideas from communication theory predict that groups differentiated by their media use may have quite different exposure to information about emerging issues.

Mass media coverage of nanotechnology risks is still nascent. While coverage, in general, has increased dramatically in recent years (Gorss and Lewenstein 2005; Stephens 2004), the reports continue to be largely positive, with little attention paid to potential risks. In a dedicated survey on nano risks in national media sources, researchers found that only 121 of almost 400 nanotechnology news stories were about social or physical risks, and even among those 121 , only $33 \%$ of the paragraphs presented negative aspects, the remainder being either neutral or even positive about the technology (Friedman and Egolf 2005). "Booster" coverage of benefits seems to characterize early coverage of many emerging technologies. Only about 7\% of approximately 3,600 U.S. and U.K. news reports on nanotechnology from 2000 to 2006 mention risks at all; of the 163 U.S. news reports mentioning any risks, 111 mentioned environmental risks, 122 mentioned health risks, and 107 mentioned a variety of "societal risks" (Friedman and Egolf 2008).
The Social Amplification of Risk Framework also contends that psychological, social, and cultural aspects need to be considered in policy-making. Traditional risk analysis has tended to neglect not only these influences but also their potential to create perceptual "ripples" in a society. These ripples are created when proposed changes resonate in some fashion with the public. This resonance could be innate, springing from the person's psychological schema, their demographic background, or their particular cultural worldview (Slovic et al. 2004). Or it could be externally derived through a third person effect (Paul et al. 2000) whereby individuals feel that the changes caused by the new technology will affect others more greatly than themselves, motivating those individuals to act to protect their broader community. As one group reacts to these perceived changes, it may create a ripple effect that moves to another group that then reacts in a similar fashion (Kasperson and Kasperson 2005). While these ripples sometimes appear to present a significant obstacle for policy makers, they, in fact, serve as a protective mechanism for societies. Once triggered, the ripples expose the fuller scope of the impacts caused by a new technology and again highlight the need for public input into the decision-making process.

However, to date, nanotechnology appears to be an attenuated risk rather than an amplified one. Despite considerable expert opinion suggesting that nanotechnology may have substantial health and environmental implications, the general public continues to be largely neutral or even optimistic about it (See, e.g., Scheufele et al. 2009; Hart Research Associates, Inc 2008; Cobb and Macoubrie 2004). While public concern about nanotechnology's risks has recently begun to rise among our panel members, the increase has been relatively modest, and has varied for different media consumption groups.

\section{Methods}

The target area for this study included metropolitan Columbia, South Carolina, the state capital, and other rural and urban areas in the northwest quadrant of the state. The University of South Carolina, Columbia, has a nanotechnology center, and has initiated a variety of associated public awareness activities 
directed both at students and at members of the broader community; thus, some of our panel members (though by no means all of them) would have had opportunities to hear something about nanotechnology research or read about it in their local newspapers. (Initially, we expected that over time, this might influence popular awareness in the region, although there is no direct evidence of this to date.)

Rather than rely on a random sample, we recruited panelists from a variety of different local groups to incorporate participants of different backgrounds. As community leaders, we included members of the Kiwanis Club and the Chamber of Commerce in Columbia; as panelists with specific religious affiliations, we recruited members of an African-American church and a mainstream Baptist church where our student interviewers had contacts; as members of the environmentalist population, we chose regional Sierra Club chapter members; and as non-affiliated ordinary citizens, we chose members of the staff of a day care facility and a group of American Cancer Society volunteers. Use of these groups helped ensure that the study participants represented a broad range of views; however, the sample size was not sufficient to justify analysis of each group by itself.

Gaining truly random samples with acceptable response rates for any survey effort is becoming increasingly difficult; gaining a truly random sample for an intensive panel study effort involving face-toface interviews and multiple surveys over time is literally impossible. Instead, we focused on the goal of including as broad as possible a range of participants recruited through a variety of community-based organizations in our target area. Although they did not officially represent the views of these organizations, the diverse affiliations secured through this recruitment strategy help insure a variety of perspectives. Our goal throughout has been to supplement other national survey efforts by studying a smaller group of people more intensely over time, to observe where they get information and how they form opinions. The results are not based on a random sample, and therefore specific numerical results are not generalizable; however, we intend that our final conclusions about patterns of information use and opinion development will have broader applicability.

As incentives, participants were offered a \$25 initial payment in the form of a donation to the organization through which they were recruited. A second $\$ 25$ payment will go to the same group for those participants who continue for the 3- to 4-year life of the study. The rationale for this procedure is that persons who might not participate in exchange for a small cash payment to themselves could be motivated to participate on behalf of an organization to which they belong and whose goals they support. A series of focus group discussions conducted with citizens in three U.S. cities (Priest and Fussell 2006) and eight depth interviews with scientific experts, both completed in 2005, along with 33 earlier interviews with undergraduate students (also in South Carolina), guided the choice of risk and benefit areas to be included.

In order to gain additional perspective on how our panelists might be similar to or different from other groups, we also compare their baseline perceptions of risk, benefit, and need for regulation to those of a group of 177 published nanoscience experts (including scientists, engineers, and social science/humanities scholars) that we had surveyed in a separate email-based study a few months prior to the initiation of this project (Besley et al. 2008).

We conducted the in-depth interviews with all 76 panelists in summer of 2007 (referred to as Time 1 or T1 throughout this article), incorporating the quantitative survey instruments that were designed to be supplemented by later rounds of data collection. Our first follow-up was conducted in spring of 2008 (referred to here as Time 2 or T2), providing some sense of the opinion trajectory, so far. Our study is specifically concerned with the influence of media messages, information-seeking, and interpersonal discussion on opinion formation. While we explore the issue of media use further below, our primary goal is not to attempt direct measurement of the "effects" of media use. Instead, we sought to study how citizens from diverse backgrounds actually come to grips with newly emerging technologies, given varied communication influences, but absent the assumption that media would dominate them. Our intent is to continue following these individuals for an additional 2-3 years.

Five doctoral students from the University of South Carolina College of Mass Communications and Information Studies, who conducted the initial depth interviews and simultaneously collected baseline quantitative data, helped identify the groups to be used. In order to maximize the likelihood of 
recruitment success and good interviewer rapport, each of the doctoral students interviewed members of the groups with whom they had the closest personal identification (e.g., an African-American student recruited and interviewed the African-American church group members, a student interested in the environment recruited and interviewed the Sierra Club members, and so on).

All interviewers participated in an intensive oneday training workshop at which materials were distributed, appropriate interviewing techniques were presented, and participants were given the opportunity to practice their interviewing skills. While variation in interviewer strengths and styles likely persisted, the training assured some level of consistency across interviews.

The interviews were carefully structured; they began with completely open-ended questions about what nanotechnology might be and what mental images were associated with the term, then provided participants with additional information based on the NNI definition of nanotechnology, then proceeded with a brief written survey to secure the baseline quantitative data, and closed with additional openended questions to further probe these initial reactions. All quantitative results are reported on 5-point scales.

All statistical comparisons were performed using SPSS $t$-test routines; citizens at T1 versus scientists were compared using two-tailed independent samples tests, while $\mathrm{T} 1$ versus $\mathrm{T} 2$ citizen perceptions were compared using two-tailed paired samples tests. MANOVA analysis using all three independent and all three dependent variables produced almost identical results, so for simplicity, we present the results for each $t$-test separately.

\section{Findings}

Initial findings suggest that our participants began with very little information about nanotechnology (Priest and Kramer 2008). In most cases, they nevertheless conveyed a surprisingly accurate general idea of the term before receiving additional information from the interviewers. For example, they generally understood that nanotechnology refers to very small technology that might have applications in electronics, computers, medicine, and other areas. They also had a general "template" of expectations for new technology that they applied to this novel example, a template that (as stated above) assumes technology brings both risks and benefits. While some participants had to be "drawn out" to offer their perspective on this novel set of technologies for which they often had only general knowledge of technology to serve as context, most did not have sustained difficulty in discussing nanotech once they got started. (This was in contrast to our experiences with the earlier student interviews, where our undergraduate interviewees seemed much more reluctant to offer an opinion.)

Figure 1a-c compares the perceived levels of risk, benefit, and need for regulation of panel members with those of the surveyed experts. With respect to benefits (1a), the citizens' panel members at $\mathrm{T} 1$ expect slightly more benefit in six of seven areas assessed (all but new material development; n.s. except for natural resource conservation at $p=0.02$ and energy production at $p=0.01)$. Citizen benefit perceptions at $\mathrm{T} 2$ follow the same pattern; see below. This is consistent with an understanding of U.S. culture as generally pro-technology and of nanotechnology as largely lacking the problematic ethical associations of biotechnology (Priest and Fussell 2006). The striking thing is, indeed, how closely our panelists-including both environmentalists and religious conservativesresembled nanotechnology experts in general expectations for nano-technology benefits, and how little these benefit perceptions changed over time.

Risks present a slightly different picture (1b), however, with panelists at $\mathrm{T} 1$ seeing more risk than scientists for six out of the eight areas (four significant at $p \leq 0.04$ and two n.s.) and less risk than scientists only for human health and environmental pollution (both n.s.). Risk perceptions for panelists at $\mathrm{T} 2$ increased noticeably, as will also be discussed further below. The perceived need for regulation (1c), however, most sharply divides the T1 citizen panel members from the expert respondents across six different areas assessed $(p \leq 0.001$ in each case), a pattern that continues at $\mathrm{T} 2$.

Visual inspection easily confirms that for the nonexpert respondents, perceptions of societal risks are on the rise, as are those for health risks, while benefit expectations and most opinions about regulation remain stable. Panel members' perceptions of risk increased from $\mathrm{T} 1$ to $\mathrm{T} 2$ across all eight items, a period of only approximately 9 months, with the largest 

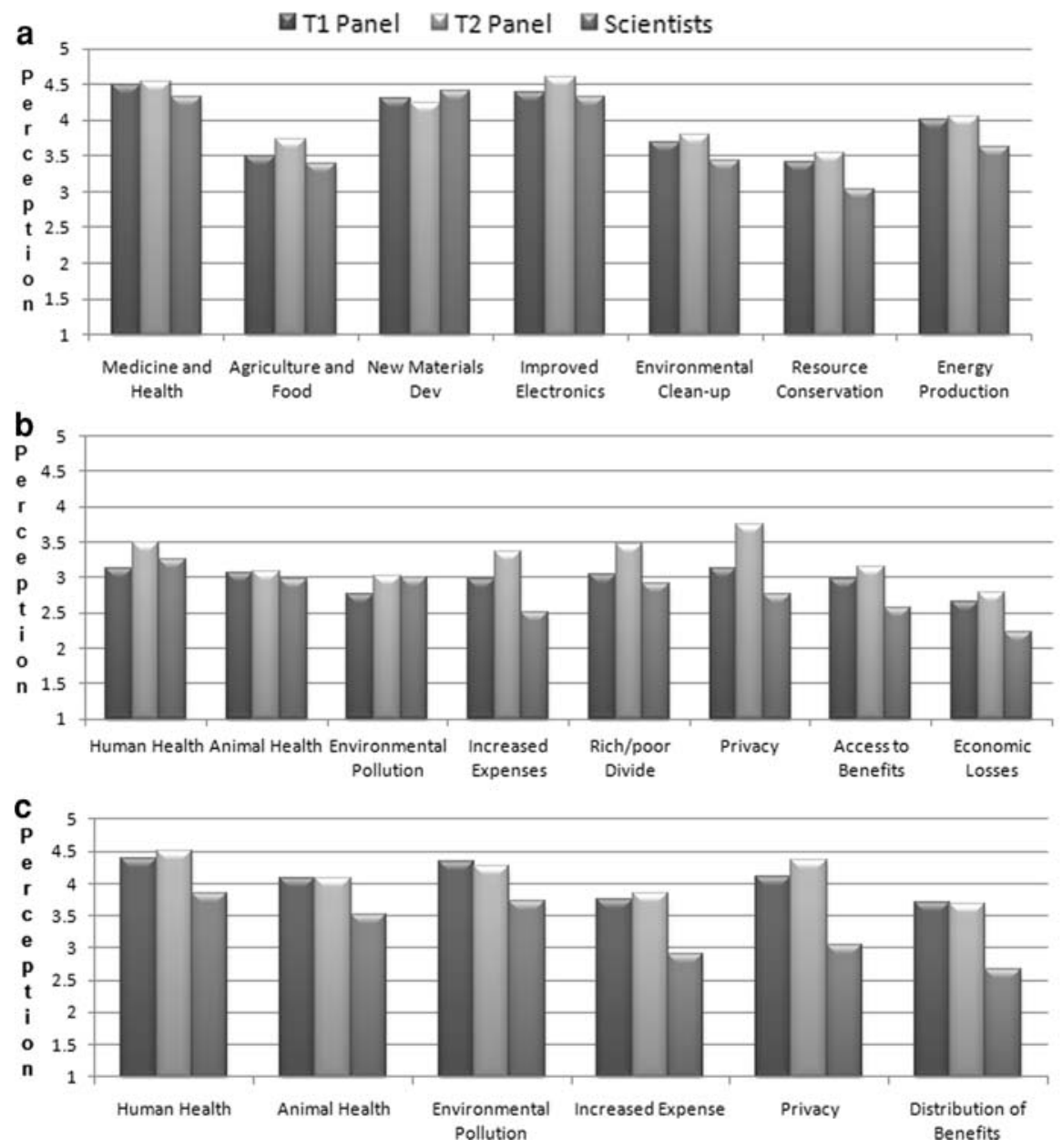

Fig. 1 Mean panelist and scientist perceptions. a Panel responses to the question "How beneficial do you believe nanotechnology will be for society over the next 20 years in each of the following areas," and scientist responses to the question "How important do you believe nanotechnology's benefits will be for society over the next 20 years in each of the following areas." b Panel responses to the question "How risky do you believe nanotechnology will be for society over the 20 years with respect to each of the following areas," and scientist responses to the question "How important do you

increases for privacy issues, followed by increased expenses, human health, a "rich/poor divide," and then environmental pollution. However, only the T1$\mathrm{T} 2$ increase in privacy issues risk is statistically significant, given our small $\mathrm{N}$ (at $p=0.002$ ). The change in perceived need for regulation on privacy grounds is marginally significant at $p=0.06$.

Media use patterns among our panelists, while intriguing, so far show very little consistent relationship to perceptions of nanotechnology-related risk, believe nanotechnology's risks will be for society over the next 20 years in each of the following areas." c Panel responses to the question "How important do you believe it is to have regulations to control nanotechnology's risk in each of the following areas," and scientist response to the question "How important do you believe it is to have regulations to control nanotechnology's risks in each of the following areas." Standard deviations for benefits ranged from 0.785 to 1.155 ; for risks from 1.009 to 1.300 ; and for regulation from 0.950 to 1.399 across all groups

which would make sense based on the low level of risk reporting seen in the news media. We were unable to specifically attribute the heightened risk perceptions we observed to exposure to specific media and information. This comparison was confounded, however, by the fact that different groups of respondents began with different levels of perceived risk at T1. Reading a national paper is associated with less of an increase in perceived environmental risk from $\mathrm{T} 1$ to $\mathrm{T} 2$ ( $r=-0.349, p \leq 0.01)$, but it is likely 
that this only reflects the fact that these participants began with more environmental risk awareness, and therefore exhibited less change. Conversely, listening to talk radio is associated with more increase in perceived human health risk ( $r=0.351, p \leq 0.01$ ), but this may be because frequent talk radio listeners were initially less aware of these risks, and not because talk radio necessarily discussed them.

However, by dividing the panelists into low- and high-media exposure groups based on $\mathrm{T} 1$ data (Table 1), it becomes clear that overall, higher media exposure is consistently associated with elevated risk perceptions, and also that almost all risk perceptions among both the low-media exposure and the highmedia exposure group are rising over time. The index of media exposure used here was simply the sum of the weekly frequency of exposure our participants reported at $\mathrm{T} 1$ over eight different media: national news magazines, national newspapers, regional newspapers, local newspapers, national television news, local television news, talk radio, and Internet. Participants falling at or below an index value of 23 (representing the 50th percentile out of a possible total score of 56,7 days $\times 8$ media) were considered "low exposure" and those at 24 or above were considered "high exposure."

We caution against over-interpreting these results; all media variables are indices of general information-seeking activity and also reflect demographic factors such as educational levels, lifestyle choices, and a range of other factors, as well as any direct message "effects." Further, so little coverage appears to be being given to risk in news reports of nanotechnology that there would be little solid basis for inferring a direct effect under any circumstances. Nevertheless, it is worth noting that the high exposure group begins at $\mathrm{T} 1$ with risk perceptions that are often close to or higher than those of the lowexposure group at $\mathrm{T} 2$, and at $\mathrm{T} 2$ an obvious "risk gap" remains between the two groups.

Equally striking is the fact that for both the lowexposure group and the high-exposure group, almost all risk perceptions are increasing, but the patterns are distinct. The low-exposure group had a statistically significant increase in risk perception for privacy only, a comparison exhibiting the greatest absolute
Table 1 Comparison between low- and high-media exposures respondents (those below vs. above the 50th percentile for all panelists participating at $\mathrm{T} 1 ; 8$ separate media use indexes combined; all risk perception data reported on 5-point scale from $1=$ "not important" to $5=$ "very important" in response to question: "How risky do you believe nanotechnology will be for society over the next 20 years with respect to each of the following areas?")

\begin{tabular}{|c|c|c|c|c|c|}
\hline \multirow[b]{3}{*}{ In the area of } & \multicolumn{5}{|c|}{ Perceived 20-year risk (5-point scale) of nanotechnology for respondents characterized by: } \\
\hline & \multicolumn{2}{|c|}{ Low-media exposure } & \multicolumn{2}{|c|}{ High-media exposure } & \multirow{2}{*}{$\begin{array}{l}\text { "Risk gap" } \\
\text { T2 }\end{array}$} \\
\hline & $\mathrm{T} 1$ & $\mathrm{~T} 2$ & $\mathrm{~T} 1$ & $\mathrm{~T} 2$ & \\
\hline Human health & 3.04 & 3.25 & 3.18 & $3.75^{\mathrm{a}}$ & +0.50 \\
\hline Animal health & 3.08 & 2.96 & 2.96 & 3.21 & +0.25 \\
\hline Environmental pollution & 2.56 & 2.88 & 2.89 & 3.14 & +0.26 \\
\hline Expenses & 2.92 & 3.20 & 2.96 & $3.57^{\mathrm{b}}$ & +0.37 \\
\hline Rich/poor country divide & 2.80 & 3.00 & 3.50 & 3.89 & +0.89 \\
\hline Privacy issues & 2.88 & $3.68^{\mathrm{c}}$ & 3.39 & $3.93^{\mathrm{d}}$ & +0.25 \\
\hline Access issues & 2.76 & 2.92 & 3.39 & 3.32 & +0.40 \\
\hline Economic insecurity & 2.36 & 2.72 & 2.93 & 2.82 & +0.10 \\
\hline
\end{tabular}

The "risk gap" represents the degree to which high media exposure respondents continue to perceive more risk than low-media exposure respondents at T2. Significance levels of $p=0.100$ or below based on 2-tailed $t$-tests between T1 and T2 values for perceived risk by type of risk separately for each exposure group are indicated in footnotes a-d. Includes only respondents who remained active in study at $\mathrm{T} 2(N=57)$

${ }^{\mathrm{a}} p=0.080$
${ }^{\mathrm{b}} p=0.027$
${ }^{\mathrm{c}} p=0.041$
${ }^{\mathrm{d}} p=0.037$ 
Table 2 Changes in risk perception for eight nanotechnology-related risk areas as a function of information-seeking behavior among South Carolina citizens' panel members (only significance levels at or below 0.100 are shown)

\begin{tabular}{|c|c|c|c|c|c|c|c|c|}
\hline & \multicolumn{8}{|c|}{ Unit change (on 5-point scale) for perceived risk of nanotechnology for: } \\
\hline & $\begin{array}{l}\text { Human } \\
\text { health }\end{array}$ & $\begin{array}{l}\text { Animal } \\
\text { health }\end{array}$ & Environment & $\begin{array}{l}\text { Impact on } \\
\text { expenses }\end{array}$ & $\begin{array}{l}\text { Rich/poor } \\
\text { divide }\end{array}$ & $\begin{array}{l}\text { Privacy } \\
\text { issues }\end{array}$ & $\begin{array}{l}\text { Access } \\
\text { issues }\end{array}$ & $\begin{array}{l}\text { Economic } \\
\text { disruption }\end{array}$ \\
\hline "Seeker" mean perceived risk increase & +1.13 & +0.80 & +0.60 & +0.60 & +1.13 & 0.00 & +0.07 & +0.13 \\
\hline "Non-seeker" mean perceived risk increase & +0.09 & -0.18 & +0.09 & +0.26 & +0.06 & +0.91 & +0.03 & +0.09 \\
\hline $\begin{array}{l}\text { Significance of two-tailed } t \text {-test } \\
\text { for equality of means }\end{array}$ & 0.031 & 0.068 & n.s. & n.s. & 0.007 & 0.059 & n.s. & n.s. \\
\hline
\end{tabular}

gap from T1 to T2, whereas the high exposure group had statistically significant increases for expenses of everyday life as well as privacy and a marginally significant increase in perceived risk in the area of health. While we were unable to discern patterns attributable to type of media consumed (e.g., national newspapers versus Internet versus local TV news), more active media consumers did exhibit heightened risk perception over time in more categories, as well as more absolute risk perceived.

We also assume that audiences form interpretive communities that bring quite different social values and cultural understandings to bear on interpreting the same message (Priest 2008). The differences in media consumption, we observe here also reflect lifestyle differences; the regular national newspaper reader likely has a different background and news coverage expectation from the regular local newspaper reader, for example. However, media is not the only influence on opinion formation. A long tradition in communication research, beginning with voting studies by Lazarsfeld et al. (1944) and Katz and Lazarsfeld (1955), suggests that interpersonal communication is often more influential than mass media communication in changing attitudes. A more recent and increasingly well-developed trend is to look at the impacts of information-seeking behavior. We investigated both of these influences for our panel.

The impact of information-seeking is a significant $(p \leq 0.05)$ or marginally significant $(p \leq 0.10)$ predictor of change for four out of eight of the risk perceptions studied. Whether statistically significant or not, information-seeking is associated with an increase in perceived risk in all but one case, that of privacy, which was marginally significant ( $p=0.059)$, but in the opposite direction-i.e., more active information-seekers were not more likely to have rising perceptions of privacy risk from $\mathrm{T} 1$ to $\mathrm{T} 2$ and may be so less. For human health risk, seeking is a significant predictor of a rise in increased risk perception at $p=0.031$; for a rich/poor country divide, the equivalent figure is $p=0.007$ (Table 2).

The "picture" for an included discussion variable at $\mathrm{T} 2$ is clear to a lesser extend. Respondents at T2 were asked whether they recalled discussing nanotechnology with anyone since $\mathrm{T} 1$; just over half (55\%) said no. Those who reported discussing nanotechnology with others between $\mathrm{T} 1$ and $\mathrm{T} 2$ perceive higher risk in the areas of human health, animal health, environmental pollution, expenses, and economic uncertainty, and less risk in the areas of privacy and access. However, none of these relationships is statistically significant, based on comparison of those who recall having discussions versus those who do not (Table 3). We look forward to the opportunity to look at this relationship again once further longitudinal data have been obtained.

\section{Discussion}

What is the "correct" level of risk that should be seen here? We are more interested in understanding the nature of people's perceptions than in evaluating them against a hypothetical scale of accuracy. We do not claim that elevated risk perceptions represent a distortion nor do we claim that they do not. Policy makers interested in responding appropriately to public concerns might note, nevertheless, the more rapid rise in what we have termed "societal risks" in comparison to those associated with health and environment. While evidence continues to accumulate that health and environmental effects need attention, ordinary citizens also have additional concerns. At this point, in our panel study, these concerns are highest for erosion of privacy, with the 
Table 3 Changes in risk perception for eight nanotechnology-related risk areas as a function of whether or not respondent has discussed nanotechnology with others, among South Carolina citizens' panel members

\begin{tabular}{|c|c|c|c|c|c|c|c|c|}
\hline & \multicolumn{8}{|c|}{ Unit change (on 5-point scale) for perceived risk of nanotechnology for: } \\
\hline & $\begin{array}{l}\text { Human } \\
\text { health }\end{array}$ & $\begin{array}{l}\text { Animal } \\
\text { health }\end{array}$ & Environment & $\begin{array}{l}\text { Impact on } \\
\text { expenses }\end{array}$ & $\begin{array}{l}\text { Rich/ } \\
\text { poor } \\
\text { divide }\end{array}$ & $\begin{array}{l}\text { Privacy } \\
\text { issues }\end{array}$ & $\begin{array}{l}\text { Access } \\
\text { issues }\end{array}$ & $\begin{array}{l}\text { Economic } \\
\text { disruption }\end{array}$ \\
\hline "Discusser" mean perceived risk increase & +0.56 & +0.36 & +0.44 & +0.56 & +0.32 & +0.28 & -0.24 & +0.20 \\
\hline "Non-discusser" mean perceived risk increase & +0.27 & -0.13 & +0.16 & +0.32 & +0.32 & +0.97 & +0.29 & +0.06 \\
\hline
\end{tabular}

None of the differences are statistically significant at the 0.100 level or below, however

human health concerns and concerns over a rich/poor country divide about tied for second place. This is the case despite a relative dearth of news coverage of nanotechnology and its risks (Friedman and Egolf 2008).

While the patterns we observed may reflect general ambient concerns about social trends, as well as general expectations for technology that are not specifically limited to nanotechnology, we consider them important evidence that societal considerations matter. When we discuss risks and associated ethical considerations within the expert community, we most commonly think in terms of physical hazards-dimensions that threat human health or environmental integrity. Our regulatory system is beginning to respond to these risks for nanotechnology, despite great challenges and uncertainties. However, we do very little to address other perceived societal concerns, such as erosion of privacy or economic impacts. Public discussion of nanotechnology (and, for that matter, all technology) should expand to consider broader social impacts by using an "expanded vocabulary of risk" that helps legitimize these concerns. Whether or not supportable by evidence or borne out by future events, all such public concerns will contribute (directly or indirectly) to the acceptability or unacceptability of future technology.

It remains difficult, even after reviewing the interview material, to fully grasp why a large proportion of Americans associated privacy erosion with nanotechnology; it may have to do either with miniaturization in electronics or with the capacity of those electronics to store increasing amounts of medical and financial information, or it may represent a background concern with little logical connection to this specific class of technologies. The concern with economic disparity is in some ways equally puzzling; in retrospect, we have to wonder what our respondents understood by a "rich/poor country divide." Yet, in a crumbling economy, heightened awareness of the potential economic dimensions of any technology (for better or for worse) is hardly surprising. The technology planning process in the U.S. (as elsewhere) clearly does not do enough to understand, let alone address, the association of these broad societal issues with technological change.

We recognize that these results may have been influenced by respondent sensitization (i.e., that these respondents may have reacted to any nanotechnology information they came across differently by virtue of their participation in the study), and that the study is also based on a non-random sample; therefore, its elements are not necessarily generalizable to any population. Nevertheless, we believe that the study accurately captures important patterns in the initial way non-expert groups respond to information concerning nanotechnology and possibly other newly emerging technologies.

Acknowledgments In addition to co-author Victoria Kramer, who coordinated this part of the effort, the doctoral students who conducted the baseline data gathering were Kim Smith, Heidi Campbell, Dan Walsh, and Mary McLaughlin, all of the University of South Carolina, Columbia. We are very grateful for their invaluable contributions to this project. This research was originally supported by NSF grant \# 0531160 to the University of South Carolina under a subaward to the University of Nevada, Las Vegas.

\section{References}

Besley J, Kramer V, Priest S (2008) Expert opinion on nanotechnology: risk, benefits, and regulation. J Nanopart Res 10:549-558

Cobb MD, Macoubrie J (2004) Public perceptions about nanotechnology: risks, benefits, and trust. J Nanopart Res 6:395-405 
Entman RM (1993) Framing: toward clarification of a fractured paradigm. J Commun 43(4, Autumn):51-58

Friedman SN, Egolf BP (2005) Nanotechnology: risks and the media. IEEE Technol Soc Mag 24(4, Winter):5-11

Friedman SN, Egolf BP (2008) Mass media coverage of nanotechnology: indicators about environmental and health risks and regulatory issues. Data provided by the authors and presented at NBER Conference on Emerging Industries: Nanotechnology and NanoIndicators, Cambridge, MA

Gorss J, Lewenstein BV (2005) The salience of small: nanotechnology coverage in the American press, 1986-2004, presented to the International Communication Association, New York

Hart Research Associates, Inc (2008) Awareness of and attitudes toward nanotechnology and synthetic biology. A report of findings conducted on behalf of: Project on Emerging Nanotechnologies, The Woodrow Wilson International Center for Scholars. Available at http:// www.nanotechproject.org/process/assets/files/7040/finalsynbioreport.pdf. Accessed May 2009

Kasperson JX, Kasperson RE (2005) The social contours of risk, vol I: publics, risk communication \& the social amplification of risk. Earthscan, Sterling, VA

Kasperson RE, Renn O, Slovic P, Brown H, Emel J, Goble R, Kasperson JX, Ratick S (1988) The social amplification of risk: a conceptual framework. Risk Anal 8(2):177-187

Katz E, Lazarsfeld PF (1955) Personal influence. The Free Press, New York

Lazarsfeld PF, Berelson B, Gaudet H (1944) The people's choice: how the voter makes up his mind in a presidential campaign. Columbia University Press, New York

McCombs ME, Shaw DL (1993) The evolution of agendasetting research: twenty-five years in the marketplace of ideas. J Commun 43(2):58-67

National Science Foundation (2008) Science and engineering indicators 2008. National Science Foundation, Washington

Paul B, Salwen MB, Dupagne M (2000) The third-person effect: a meta-analysis of the perceptual hypothesis. Mass Commun Soc 3(1):57-85
Powell MC (2007) New risk or old risk, high risk or low risk? How scientists' standpoints shape their nanotechnology risk frames. Health Risk Soc 9:173-190

Priest S (2008) North American audiences for news of emerging technologies: Canadian and US responses to bio- and nanotechnologies. J Risk Res 11:877-889

Priest S, Fussell H (2006) Nanotechnology: constructing the public and public constructions. Paper presented at annual meeting, Association for Education in Journalism and Mass Communication

Priest S, Kramer V (2008) Making sense of emerging nanotechnologies: how ordinary people form impressions of new technology. Paper presented at annual meeting, Association for Education in Journalism and Mass Communication

Scheufele DA, Corley EA, Shih T, Dalrymple KE, Ho SS (2009) Religious beliefs and public attitudes to nanotechnology in Europe and the US. Nat Nanotechnol 4(2):91-94

Service RF (2008) Can high-speed tests sort out which nanomaterials are safe? Science 321:1036-1037

Shatkin J (2008) Nanotechnology: health and environmental risks. CRC Press (Taylor \& Francis Group), Boca Rotaon, FL

Slovic P, Finucane ML, Peters E, MacGregor D (2004) Risk as analysis and risk as feelings: some thoughts about affect, reason, risk, and rationality. Risk Anal 24(2):1-12

Stephens LF (2004) News narratives about nano: How journalist and the news media are framing nanoscience and nanotechnology initiatives and issues. Paper presented at imaging and imagining nanoscience \& engineering conference, University of South Carolina, Columbia, SC, March 7

Tichenor PJ, Donohue GA, Olien CN (1980) Community conflict and the press. Sage Publications, Beverly Hills

Tuchman G (1978) Making news: a study in the construction of reality. Free Press, New York 